\title{
Conjugated Oligomers with Alternating Heterocycles from a Single Monomer: Synthesis and Demonstration of Electroluminescence
}

\author{
Sara Urrego-Riveros, ${ }^{a, b, f}$ Matthias Bremer, ${ }^{c}$ Jonas Hoffmann, ${ }^{a, b, d}$ Anne Heitmann, ${ }^{a, b}$ Thibault \\ Reynaldo, ${ }^{\mathrm{d}}$ Janek Buhl, ${ }^{\mathrm{c}}$ Paul J. Gates, ${ }^{\mathrm{e}}$ Frank D. Sönnichsen, ${ }^{\mathrm{f}}$ Muriel Hissler, ${ }^{\mathrm{d}}$ Martina Gerken, ${ }^{\mathrm{c}}$ \\ Anne Staubitz ${ }^{\mathrm{a}, \mathrm{b}, \mathrm{f}} *$ \\ Conjugated oligomers based on two different heterocycles are typically prepared by step growth polycondensation cross- \\ coupling methods from two monomers $\mathrm{X}-\mathrm{Cycle}^{1}-\mathrm{X}$ and $\mathrm{M}-\mathrm{Cycle}^{2}-\mathrm{M}$ with no control of the regioselectivity. In this work, we \\ used a new synthetic strategy that involves an extremely chemoselective reaction of a dielectrophilic compound, \\ $\mathbf{X}^{1}-$ Cycle $^{1}-\mathbf{X}^{2}$, with a dinucleophilic component, $\mathbf{M}^{1}-\mathrm{Cycle}^{2}-\mathbf{M}^{2}$, under Stille conditions. The resulting monomers, \\ $\mathrm{X}^{1}$-Cycle ${ }^{1}-$ Cycle $^{2}-\mathrm{M}^{2}$ are di-heterocyclic push pull monomers that still contain a nucleophilic site (boronic acid) and \\ electrophilic site (bromide) and are set up for a controlled polymerization under Suzuki conditions. In this way, two \\ semiconducting oligomers, based on thiophene / benzene and thiophene / pyridine motifs were synthesized. Both \\ oligomers were characterized in terms of their, thermal, electrochemical, absorption, emission and electroluminescence \\ properties.
}

\section{Introduction}

Organic semiconductors are promising functional materials for applications in electronic devices such as light emitting diodes (OLED's), field effect transistors (OFET's) or photovoltaic solar cells. $^{1-9}$ For example, oligo and polythiophenes have been widely used as semiconductors due to their electron rich character, high conductivity $\left(>10^{5} \mathrm{~S} / \mathrm{cm}\right)^{10}$ and band gaps $\left(E_{\mathrm{g}}\right)$ ranging between 1 and $3 \mathrm{eV} .{ }^{11,12}$ Many polythiophenes show a high aggregation in solid-state leading to high charge mobilities. ${ }^{13,14}$ However this aggregation can lead to nonradiative decay pathways, such as intersystem crossing or internal conversion into the ground state, which decreases the quantum yield of oligo- and poly-thiophenes and limits their utilization in OLEDs. ${ }^{11,15}$

To overcome these limitations to be utilized in OLEDs, first of all, the aggregation in the solid state can be suppressed. This can be achieved by designing specific copolymers of thiophenes with other conjugated molecules, to prevent

a. Institute for Organic and Analytical Chemistry, University of Bremen, Leobener Str.7 NW2C, 28359 Bremen, Germany.Email: Staubitz@uni-bremen.de

${ }^{b .}$ University of Bremen, MAPEX Center for Materials and Processes, Bibliothekstr. 1, 28359 Bremen, Germany.

c. Institute of Electrical Engineering and Information Technology, University of Kiel, Kaiserstr.2, 24143 Kiel, Germany.

${ }^{d .}$ Institut des Sciences Chimiques de Rennes, UMR 6226, CNRS-Université de Rennes 1, Campus de Beaulieu, 35042 Rennes Cedex, France.

e. School of Chemistry, University of Bristol, Cantock's Close, Bristol BS8 1TS, UK

f. Otto-Diels-Institute for Organic Chemistry, University of Kiel, Otto-Hahn-Platz 4, 24098 Kiel, Germany.

Electronic Supplementary Information (ESI) available. See DOI: $10.1039 / \mathrm{x} 0 \mathrm{xx} 00000 \mathrm{x}$ interchain interactions. ${ }^{15,} 16$ Tuning the band gap can be achieved by combining different heterocycles in the polymer chain; a push-pull system can be generated by placing an electron rich group; e.g. a thiophene unit adjacent to an electron deficient unit; e.g. another aryl group (Figure 1). Typically, this leads to a bathochromic shift in the absorption. $^{12,} 15$ However, the quantum yield may be decreased, depending on the strength of the dipoles. The push-pull combination decreases the mobility of the excitons and prevents them from quenching. In addition, non-radiative decay processes of excitons can be avoided. ${ }^{17,18}$

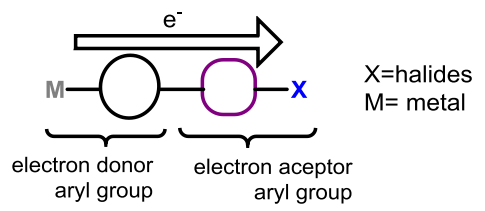

Figure 1. Design of

semiconducting polymers using the push-pull principle.

One of the most common methods to produce such copolymers is based on the step-growth polymerization between two different co-monomers $\mathbf{A}$ and $\mathbf{B}$. In such a reaction, monomer $\mathbf{A}$ would have two electrophilic sites for cross-coupling (halides, pseudohalides), whereas monomer B would have two metal functional groups (organotin, boronic acids, boronic esters, organozinc groups for example (Scheme 1a)). ${ }^{12,18}$ The polymers $\mathbf{C}$ produced by this method can be expected to have a high dispersity ( $(\boxplus)$ and a low regioregularity.

A second method is based on the chain-growth polymerization developed by McCullough and Yokozawa. The mechanism 
involves a catalyst-transfer condensation using a single monomer $\mathbf{D}$, which contains an electrophilic and nucleophilic site (Scheme 1b). ${ }^{19-21}$ With this breakthrough concept, it was possible, in the case of poly (3-alkylthiophenes), to obtain good molecular weights $\left(M_{n}\right)$, a very high regioregularity $>98 \%$, and a low dispersity; in addition, the nature of the end groups of the polymers $\mathbf{E}$ could be controlled. ${ }^{22}$ Even alternating copolymers have been obtained by this method, although in that case, only one heterocycle contained a solubilizing group, thus reducing problems of torsional defects. ${ }^{23} \mathrm{~A}$ third, novel method is based on the $\mathrm{C}-\mathrm{H}$ arylation of monomers of type $\mathbf{F}$ to produce homopolymers type $\mathbf{E}$ (Scheme $1 \mathrm{c}) \cdot{ }^{24-26}$ The $\mathrm{C}-\mathrm{H}$ bond is activated by using a catalytic system formed between a Pd, or $\mathrm{Ni}$ catalyst, a ligand and a base (e.g. Hermann's catalyst- $\mathrm{Cs}_{2} \mathrm{CO}_{3}{ }^{25}{ }^{27} \mathrm{NiCl}_{2-}$ dppe/(TMP $)_{2} \mathrm{Mg} \cdot 2 \mathrm{LiBr}^{28}$ or $\mathrm{Pd}(\mathrm{OAc})_{2}$-pivalic acid $\left.{ }^{27}\right)$. This method holds much promise and can be extended to heteropolymers of the type $A B .^{26,29}$

The aim of this work was to combine the concept of living polymerization with the advantage of combining two different building blocks in only one monomer. Therefore, monomers $\mathbf{G}$ of type M-Ar-Ar-X were designed that bear both an electrophilic and nucleophilic site allowing to obtain polymer $\mathbf{H}$ (Scheme 1d). ${ }^{19,30}$

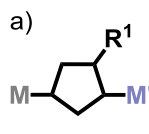

A
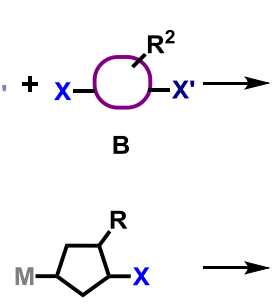

D

c)

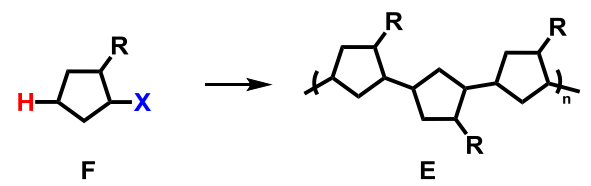

d)

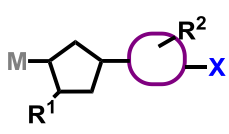

$\mathbf{G}$

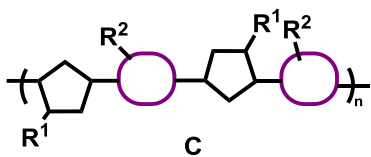

C

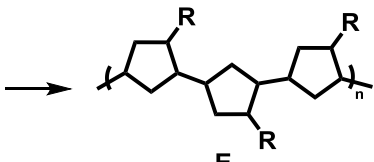

E

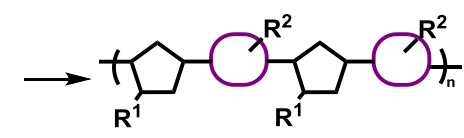

H
Scheme 1. Types of polymerization a) step-growth polymerization between $\mathbf{A}$ and $\mathbf{B}$ molecules $\mathbf{b})$ living polymerization from one type of heterocycle $\mathbf{D}$. c) direct arylation polymerization from the monomer $\mathbf{F}$ d) living polymerization of copolymers from di-heterocyclic monomers $\mathbf{G}$ (this work).

Recently, we published a monomer, which was the product of a dually nucleophilic-electrophilic selective cross-coupling reaction. ${ }^{31}$ Therein, monomer $\mathbf{3}$ was prepared to contain two different units of thiophene; a key strategic synthetic element was that dinucleophile $\mathbf{1}$ and dielectrophile $\mathbf{2}$ reacted extremely chemo specifically (Scheme 2): Only the iodo- and the tristannyl functional groups cross-coupled. However, the polymer $\mathbf{4}$ that was obtained showed a very low solubility and could only be used as a proof-of-concept. It was impossible to analyze it by solution-state NMR and the optoelectronic properties could not be measured. However by MALDI-MS, an oligomer with a mass of $2483 \mathrm{~m} / \mathrm{z}$ was detected, ${ }^{31}$ which was very promising and led us to pursue the concept of monomer formation by dually electrophile and nucleophile selective reactions for monomers that would lead to soluble polymers or oligomers. In this context, the work of Zhang and Hong should be mentioned, who at the same time as ourselves followed a similar strategy for the synthesis of a polyarene. ${ }^{32}$

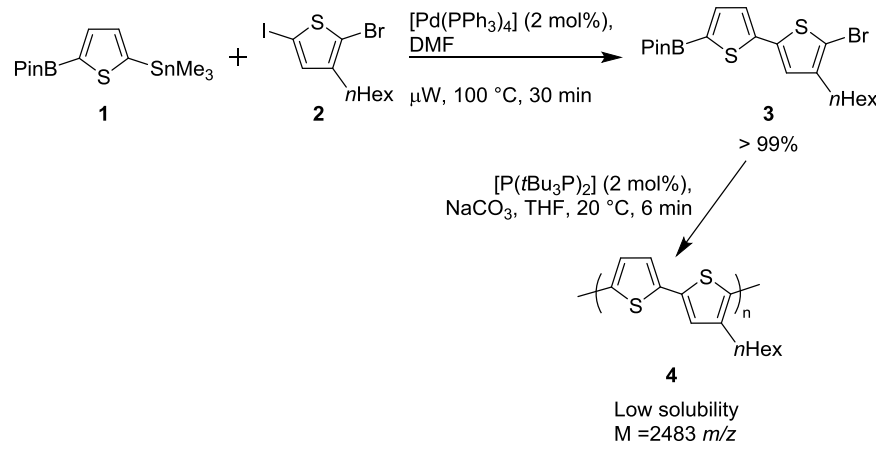

Scheme 2. Synthetic way to obtain a polymer based on a single monomer type M-Ar-Ar-X.

In this work, we report a dually nucleophilic-electrophilic selective cross-coupling reaction to prepare two monomers, $\mathbf{5}$ and $\mathbf{6}$ type $\mathbf{G}$ (M-Ar-Ar-X). The monomers $\mathbf{5}$ and $\mathbf{6}$ were designed using the concept of the push-pull principle, having an aryl or pyridine (6) moiety as an electron acceptor group. ${ }^{18}$ This part of the molecule was designed as the di-electrophilic part, whereas the thiophene moiety was designed as the electron-rich di-nucleophilic part. In order to improve the solubility of the monomers, a hexyl chain was installed at the thiophene unit and a hexyloxychain on the six-membered aromatic ring (Figure 2). The oligomers $\mathbf{0 1}$ and $\mathbf{0 2}$ were then obtained by a Suzuki cross-coupling living polymerization.

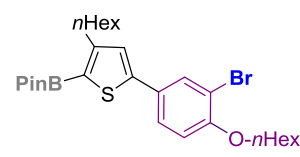

5

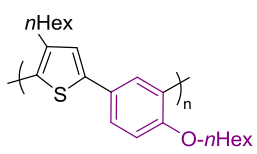

01

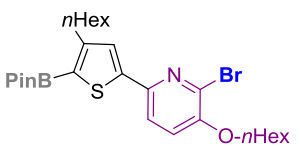

BPin $=\{-B^{\prime}{ }^{O} \overbrace{\mathrm{Me}}^{\mathrm{O}} \mathrm{Me}$

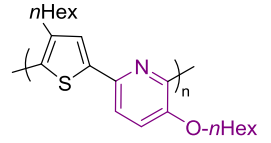

02
Figure 2. Newly prepared push pull monomers $\mathbf{5}$ and $\mathbf{6}$ and oligomers 01 and $\mathbf{0 2}$.

In addition to the synthesis, we report on the structural, optical and thermal characteristics of the obtained oligomers $\mathbf{0 1}$ and $\mathbf{0 2}$. First electroluminescence tests were performed to assess these materials as potential emission layers in OLEDs. 


\section{Results and discussion}

\section{Synthesis of the monomers}

The retrosynthetic analysis explains the high selectivity, which is required to obtain the monomer type $\mathbf{G}$ (Scheme 3 ): It is vital that in the dinucleophile $\mathrm{I}$, only metal $\mathrm{M}^{2}$ reacts and in dielectrophile $J$, only halogen $X^{2}$. Any reaction of $M^{1}$ or $X^{1}$ would lead to slightly different monomers that would be inseparable from the desired ones and, moreover, there would be no regioselectivity with respect to the solubilizing side groups $\mathrm{R}^{1}$ and $\mathrm{R}^{2}$.

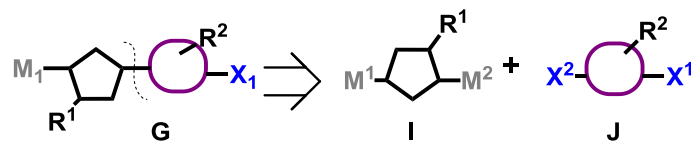

Scheme 3. Retrosynthetic pathway to obtain the desired monomers type G.

The dinucleophile $\mathbf{7}$ was prepared as reported in the literature. ${ }^{31}$ The first attempt to prepare the monomer 9 was a selective Stille cross-coupling reaction between the dinucleophile 7 and the dielectrophile 8 (Scheme 4), in a similar way to how monomer $\mathbf{3}$ was obtained (Scheme 2). However, no product was formed either with conventional or under microwave conditions. One reason might be the steric hindrance of the hexyl chain that prevents the Stille reaction between the iodo-group of $\mathbf{8}$ and the trimethylstannyl group of 7, although electronic reasons might play a role. McCullough et al. showed that 3-hexylthiophene monomers react much more readily if the $M$ functional group is in 5-position and the $X$ functional group in 2-position. They argue that the transmetallation step is favorable if the $M$ functional group is in a less steric hindered position relative to the catalyst center of the growing polymer. ${ }^{33-35}$

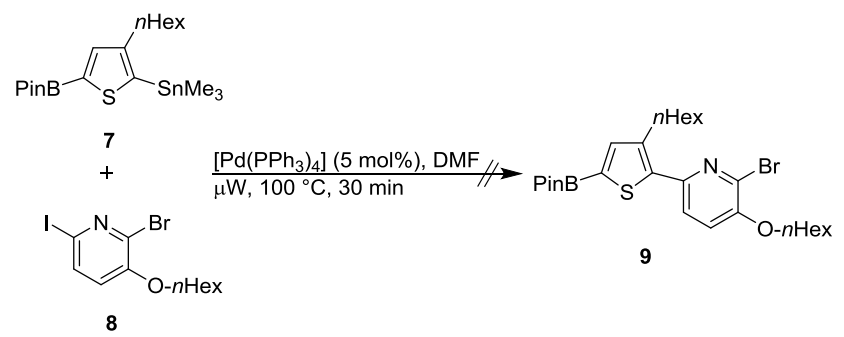

Scheme 4. Synthetic pathway to obtain monomer $9 .^{31}$

Therefore, the dinucleophile had to be redesigned. Thus, dinucleophile $\mathbf{1 3}$ was prepared (Scheme 5). The synthetic pathway involved a site-selective lithiation reaction of 3hexylthiophene (10) in 5-position, followed by quenching with $\mathrm{CBr}_{4}$ to obtain 2-bromo-4-hexylthiophene (11). ${ }^{36}$ Site-selective deprotonation followed by a lithium-boron exchange led to mononucleophile 12. In a final step, a selective Stille-Kelly coupling reaction of $12,{ }^{37}$ with $\left(\mathrm{SnMe}_{3}\right)_{2}, \mathrm{Pd}(0)$ under microwave heating led to the novel dinucleophile $\mathbf{1 3}$ in a yield of $89 \%$.

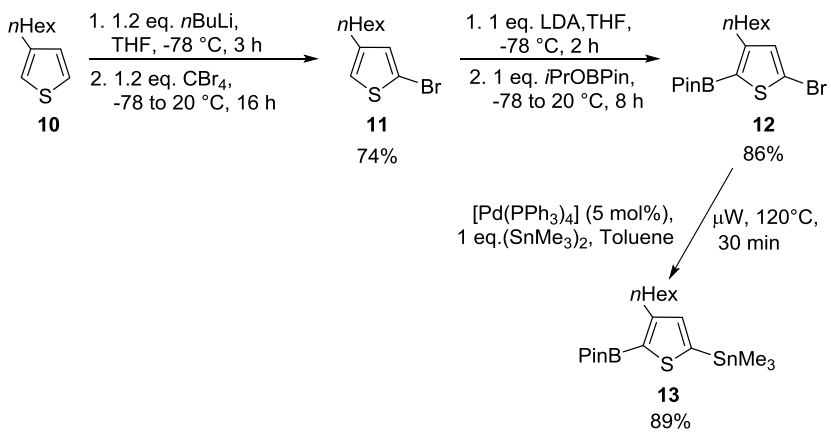

Scheme 5. Synthetic pathway to form the dinucleophile 13

For the Stille cross-coupling reaction, two dielectrophiles 16 and 19 were also required. The synthesis of the dielectrophile 16 started from the commercially available 2-bromophenol (14), which was subjected to a Williamson etherification with 1 -iodohexane and led to 15 in a yield of $94 \%{ }^{38}$ Then, a solventfree iodination of 1-bromo-2-( $n$-hexyloxy)benzene (15) was carried out to give the 1-bromo-2-(hexyloxy)benzene-5iodobenzene (16) in $80 \%$ yield (Scheme 6$).{ }^{39}$ The synthesis of dielectrophile 8 started from 2-bromopyridine-3-ol (17), which was subjected to an iodination reaction to yield the iodopyridine derivate 18 in $77 \%$. Compound 18 was then used in an alkylation reaction with 1-bromohexane to yield the dielectrophile 8 in $70 \%$ (Scheme 6). ${ }^{40}$

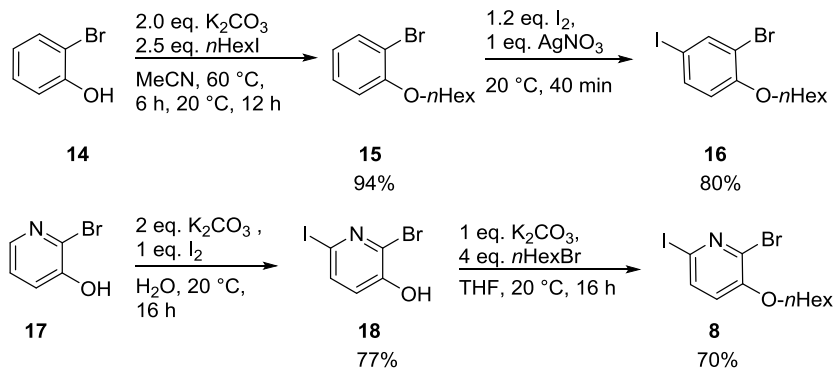

Scheme 6. Synthetic path to obtain the dielectrophiles $\mathbf{1 6}$ and $\mathbf{8}$.

The dinucleophile 13 and dielectrophiles 16 and 8 respectively, were subjected to a Stille cross-coupling reaction under microwave conditions leading selectively to the monomers 5 and $\mathbf{6}$ (Scheme 7). ${ }^{31,41}$ The high selectivity of the reaction can be explained by the use of dinucleophile $\mathbf{1 3}$, as the reaction occured selectively between the iodo and trimethyl tin group. There is less steric hindrance for the tin functional group compared to the boronic ester, and Suzukireactions would require an additional base. In addition, the C-I bonds in $\mathbf{1 6}$ and $\mathbf{8}$ are much weaker than the $\mathrm{C}-\mathrm{Br}$ bonds. 


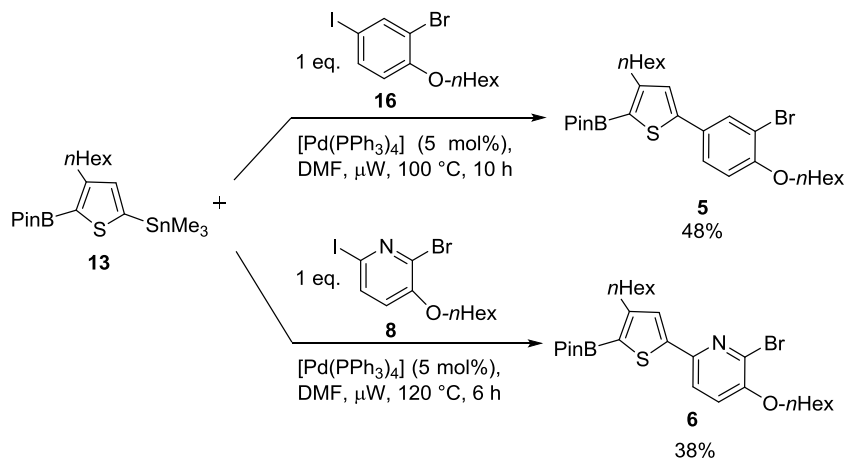

Scheme 7. Synthetic pathway to form the monomers $\mathbf{5}$ and $\mathbf{6}$ in a Stille cross-coupling reaction between dinucleophile 13 and dielectrophiles 16 and $\mathbf{8}$, respectively.

\section{Synthesis of oligomers 01 and 02.}

Polycondensation Suzuki reactions of the monomers $\mathbf{5}$ and $\mathbf{6}$ were tested with two catalysts, $\left(\left[\mathrm{Pd}\left(t \mathrm{Bu}_{3} \mathrm{P}\right)_{2}\right]\right.$ and $\left.\left[\mathrm{Pd}(\mathrm{dppf}) \mathrm{Cl}_{2}\right]\right)$ (see in $\mathrm{ESI}$ Tables SI-3 and SI-4). From these, $\left[\mathrm{Pd}\left(t \mathrm{Bu}_{3} \mathrm{P}\right)_{2}\right]$ emerged as the best system and it was used in the polymerization reactions for both monomers, which were heated at 60 and $50{ }^{\circ} \mathrm{C}$ respectively (Scheme 8$).{ }^{42}$ The crude products were precipitated from the reaction mixture with a solution of $\mathrm{HCl}$ in methanol $(1 \mathrm{M})$ and washed several times with methanol by Soxhlet extractions. The products were soluble in chloroform. Oligomer $\mathbf{0 1}$ was obtained in a yield of $46 \%\left(M_{n}=1.56 \mathrm{kDa}\right.$. $Đ=1.12, \mathrm{GPC}$ calibrated against polystyrene) and 02 in a yield of $60 \%\left(\mathrm{M}_{n}=5.39 \mathrm{kDa}, Ð=1.83\right)$, respectively. It was found by MALDI-TOF mass spectrometry that for both polymers, the end groups were $\mathrm{H}$ and $\mathrm{Br}$ (see in ESI, Figure S1-2 for 01 and SI-9 for 02).

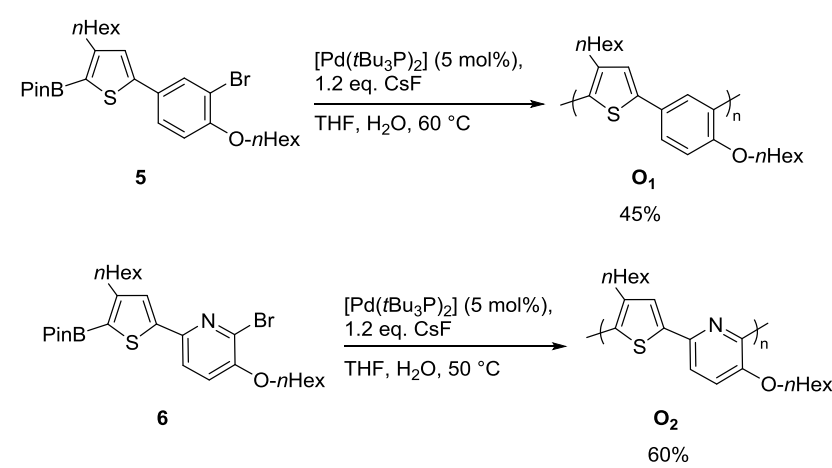

Scheme 8. Syntheses of the oligomers $\mathbf{0 1}$ and $\mathbf{0 2}$.

\section{Analysis of the oligomerization of oligomers 01 and 02 .}

To evaluate the type of kinetics of polymer chain formation, reaction monitoring studies of the polymerization were performed. Samples from the reaction mixture were taken in the course of $24 \mathrm{~h}$ for $\mathbf{0 1}$ and $\mathbf{2 7} \mathrm{h}$ for $\mathbf{0 2}$. Each sample was quenched with a solution of $\mathrm{HCl}$ in methanol $1 \mathrm{M}$ straight after removal from the reaction, extracted with DCM and split in two for measurements of GPC and ${ }^{1} \mathrm{H}$ NMR spectroscopy. The percentage of conversion for each sample, was calculated relative to the protonated products 19 and 20 that are formed by protonolysis (Scheme 9). The plots of $\%$ conversion vs. time and \% conversion vs. $M_{n}$ and $M_{n} / M_{w}$ are depicted in Figure 3 for $\mathbf{0 2}$. The conversion was calculated with respect to the consumption of product 20 observed by ${ }^{1} \mathrm{H}$ NMR spectra and from the UV-Vis/ elugram areas visualized in the 2D

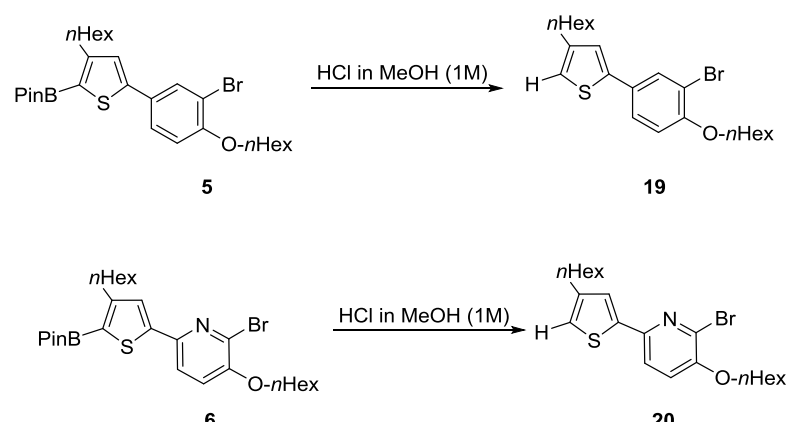

plots from the GPC measurements (See ESI).

Scheme 9. Compounds 5 and $\mathbf{6}$ were transformed into the products 19 and 20 , respectively, by treating them with $\mathrm{HCl} / \mathrm{MeOH}(1 \mathrm{M})$.

The oligomer appeared to grow approximately linearly in length during the first $9 \mathrm{~h}$, reaching $60 \%$ conversion and a $M_{n}=1.40 \mathrm{kDa}$. Then, in the period from $9 \mathrm{~h}$ to $28 \mathrm{~h}$, only very little growth in length took place, but a conversion of eventually $100 \%$ product was reached. This observation may be interpreted that the reaction had a living character until a conversion of $60 \%$. A similar behavior could be observed for 01: after $8 \mathrm{~h}$, the conversion reached $40 \%$, growing sharply until $92 \%$ in the following $16 \mathrm{~h}$ (See the ESI for Figures SI-21, 22 and 23).
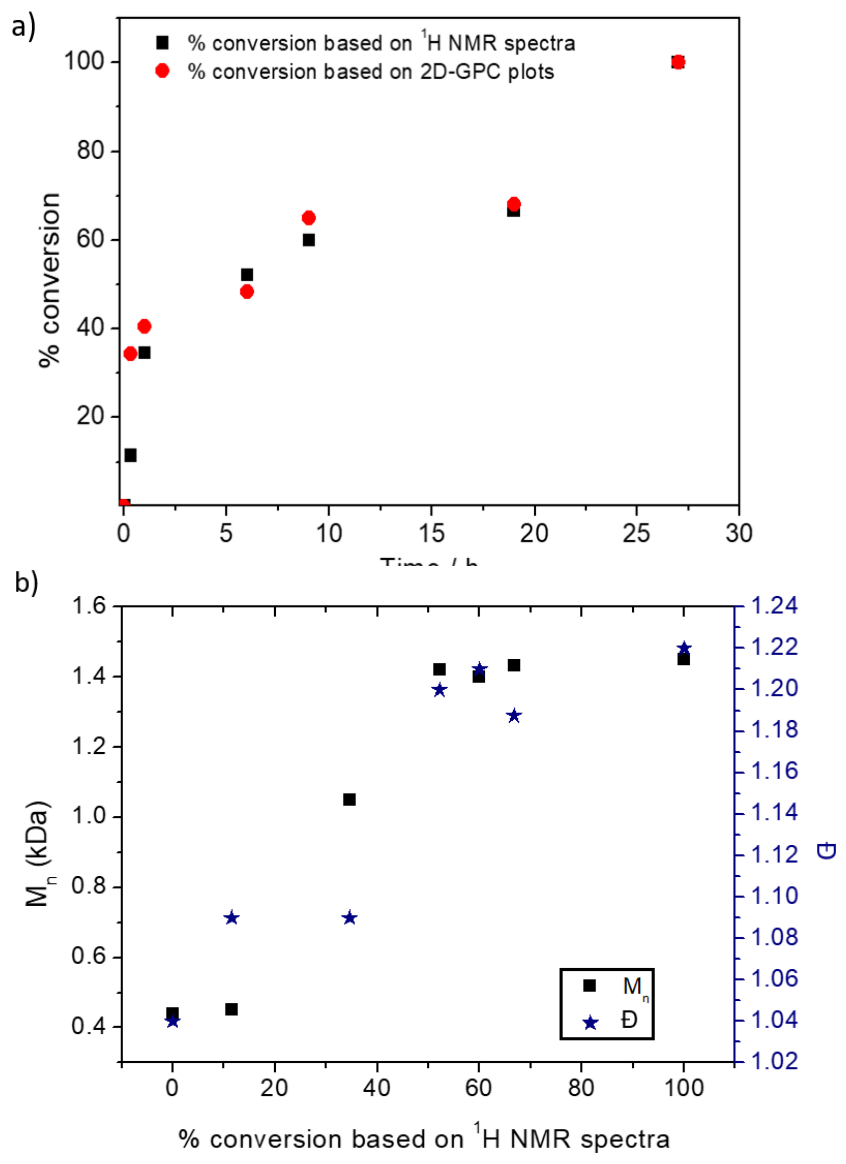

Figure 3. Plots of a) \% conversion vs. time. Calculated by the two detectors ( ${ }^{1} \mathrm{H}$ and 2D-plots GPC) and b) $M_{n}$ and $Đ$ vs. \% conversion calculated by ${ }^{1} \mathrm{H}$ 
NMR; for the polymerization of 6 with 5 mol\% of $\left[\mathrm{Pd}\left(t \mathrm{Bu}_{3} \mathrm{P}\right)_{2}\right], 1.2$ eq. CsF in THF at $50{ }^{\circ} \mathrm{C}$. The conversion was calculated relative to compound 20 (product from the quenching process with $\mathrm{HCl} / \mathrm{MeOH}$ ) based on ${ }^{1} \mathrm{H} N M R$ spectra and 2D-GPC plots.

It needs to be pointed out that although the formal classification of the polymerization kinetics is chain growth, the linear region of the quasi-living character is relatively limited, presumably because the catalyst diffuses from the growing chain more quickly that a new monomer is reacted with it. ${ }^{19,43}$ This can be attributed to the sterically relatively congested site of cross-coupling (with adjacent alkyl and alkoxy groups).

\section{Optical and electrochemical characterization}

In order to establish structure/properties relationships, the optical (UV-Vis absorption and fluorescence) and electrochemical properties of $\mathbf{O 1}$ and $\mathbf{O} 2$ were studied in $\mathrm{CH}_{2} \mathrm{Cl}_{2}$. The two oligomers $\mathbf{0 1}$ and $\mathbf{0 2}$ presented a broadband in the absorption spectrum (Figure 4). The absorption maximum observed for $02\left(\lambda_{\max }=\right.$ $387 \mathrm{~nm}$ ) was bathochromically-shifted compared to the absorption maximum of $01\left(\lambda_{\max }=318 \mathrm{~nm}\right)$ suggesting a higher extended $\pi$ conjugation in $\mathbf{0 2}$ due to a certain charge transfer character of $\pi-\pi^{*}$ transition of the thiophene-pyridine motif. A similar trend was observed for the fluorescence of the oligomers. Oligomers $\mathbf{0 1}$ and $\mathbf{0 2}$ showed fluorescence around $\mathbf{4 3 5} \mathrm{nm}$ with a small red-shift for the derivative $\mathbf{0 2}(\Delta \lambda=5 \mathrm{~nm})$. The fluorescence quantum yields measured versus quinine sulfate were moderate in solution $(10 \%$, 01 and 28\%, 02, Table 1)). Excitation spectra also confirmed the observations made for the UV-Vis absorption of oligomers $\mathbf{0 1}$ and 02. (see Figures SI-3 and SI-10). The optoelectronic properties from both oligomers in comparison with a 4-unit oligomer of thiophene (in chloroform solution: $\lambda_{\max }=372 \mathrm{~nm},{ }^{44} \lambda_{\mathrm{PL}}=494 \mathrm{~nm},{ }^{44} \Phi=0.09^{44}$ and $E_{\mathrm{g} \text { optical }}=3.33 \mathrm{eV}^{45}$ ), shows that a combination with a stronger acceptor than thiophene (pyridyl group in 02) leads indeed to a higher bathochromic shift. However, although a phenyl group is also an acceptor with respect to thiophene, ${ }^{18} \lambda_{\max }$ of 01 is hypsochromically shifted, likely due to torsional defects arising from the six-membered ring that are not sufficiently counterbalanced by an acceptor property that is lower than that of a pyridyl ring. The photoluminescence is most strongly shifted in the oligomer of oligo3-hexylthiophene.

The redox properties of oligomers $\mathbf{0 1}$ and $\mathbf{0 2}$ were investigated by cyclic voltammetry $\left(\mathrm{CH}_{2} \mathrm{Cl}_{2}, 0.2 \mathrm{M}, \mathrm{Bu}_{4} \mathrm{NPF}_{6}, \mathrm{v}=200 \mathrm{mVs}^{-1}\right.$, Table 1$)$. All compounds showed a quasi-reversible oxidation wave at relatively low potential. Compound $\mathbf{0 1}$ displayed an oxidation wave at around $+0.48 \mathrm{~V}\left(\mathrm{vs}\right.$. $\mathrm{Fc}^{+} / \mathrm{Fc}$ ) while $\mathbf{0 2}$ was slightly easier to oxidize $\left(\mathrm{E}_{\mathrm{ox}}=+0.47 \mathrm{~V}\right.$ vs. $\left.\mathrm{Fc}^{+} / \mathrm{Fc}\right)$. These electrochemical characterizations indicated that the highest occupied molecular orbital (HOMO) was energetically destabilized for oligomer $\mathbf{0 2}$ compared to the HOMO of 01 (Table 1 ). ${ }^{46}$ The reduction potentials, which are attributed to the energy of the lowest unoccupied molecular orbital (LUMO) and therefore to the $\pi^{*}$ band, were not possible to detect because the potentials were out of the electrochemical window (Figure SI-4 for
01 and Figure $\mathrm{SI}-14$ for $\mathbf{0 2}$ respectively). Hence, the reduction potential (LUMO) for both oligomers were estimated using the HOMO and optical energy gap values.

Figure 4. Normalized absorption spectra (abs.) and PL spectra of $\mathbf{0 1}$ and $\mathbf{0 2}$

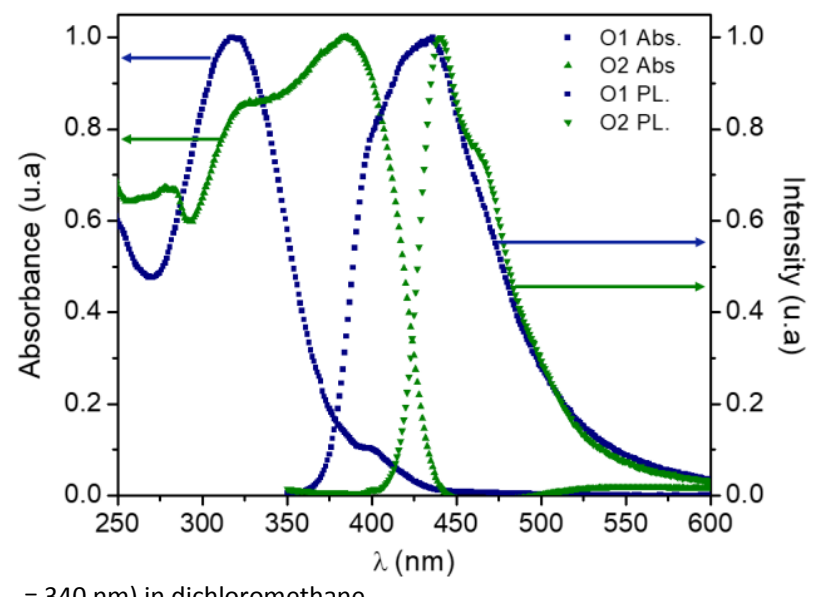

Table 1. Optical and electrochemical properties of the oligomers $\mathbf{0 1}$ and $\mathbf{0 2}$.

\begin{tabular}{c|c|c|c|c|c}
\hline Compound & $\begin{array}{c}\Phi^{a} / \\
\lambda_{\mathrm{PL}}(\mathrm{nm})\end{array}$ & $\begin{array}{c}\mathrm{E}_{\mathrm{g}} \\
(\mathrm{eV}) \exp ^{b} \\
/ \text { calc. }^{\mathrm{f}}\end{array}$ & $\mathrm{E}_{\mathrm{Ox}}(\mathrm{V})^{c}$ & $\begin{array}{c}\mathrm{E}_{\text {HOMO }} \\
(\mathrm{eV}) \\
\exp ^{d} / \\
\text { calc. }^{f}\end{array}$ & $\begin{array}{c}\mathrm{E}_{\mathrm{LUMO}} \\
(\mathrm{eV}) \\
\mathrm{Exp}^{e} / \\
\text { calc. }^{\mathrm{f}}\end{array}$ \\
\hline $\mathbf{0 1}$ & $0.10 /$ & $3.17 /$ & +0.48 & $-5.87 /$ & $-2.70 /-$ \\
& 432 & 3.95 & & -5.17 & 1.22 \\
\hline $\mathbf{0 2}$ & $0.28 /$ & $2.77 /$ & +0.47 & $-5.86 /$ & $-3.09 /-$ \\
& 442 & 3.54 & & -5.11 & 1.57 \\
\hline
\end{tabular}

${ }^{a}$ The quantum yield was calculated using a solution of quinine sulfate ( $1 \mathrm{M}$ in $\mathrm{H}_{2} \mathrm{SO}_{4}$ ) with a $\phi$ of $0.54 .{ }^{b}$ Optical band gap. ${ }^{c}$ Obtained from the cyclic voltagram of a solution of the oligomer in DCM $\left(1 \times 10^{-3} \mathrm{M}\right)$ with $\mathrm{Bu}_{4} \mathrm{NPF}_{6}(0.2 \mathrm{M}$ in DCM) as electrolyte. ${ }^{4{ }^{d}}$ The energy from the $\mathrm{HOMO}$ was calculated with the equation: $E_{\text {HOMO }}=-\left(E_{\text {onset ox. vs } \mathrm{Fc} / / \mathrm{Fc}}+5.39\right) \mathrm{eV} .{ }^{46}$ e $T$ The energy from the LUMO was calculated with the equation $E_{\text {LUMO }}=-\left(E_{g}-E_{\text {HOMO }}\right) .{ }^{46 f}$ Calculated using TD-DFT based on the trimers.

Such a difference in the optoelectronic behavior between the oligomers $\mathbf{0 1}$ and $\mathbf{0 2}$ can be related to the enhanced donoracceptor effect in $\mathbf{0 2}$, because of the higher $\pi$ acceptance of the pyridine compared to the benzene in $01 .^{18}$

\section{Computational studies}

These experimental observations were further supported by time-dependent density functional theory (TD-DFT) studies in the gas phase. To simplify this computational study, the calculations were carried out on two simplified monomer structures S1 and S2, and the corresponding dimers and trimers (Figure 5). 


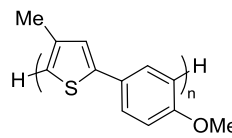

s1

S1-2: $\mathrm{n}=2$ S1-3: $n=3$ s2

S2-2: $n=2$

S2-3: $n=3$

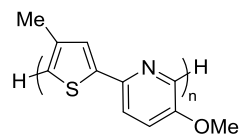

Figure 5. Monomers, dimers and trimers proposed for computationa studies. The hexyl chains from the monomers $\mathbf{5}$ and $\mathbf{6}$ were replaced by methyl groups in $\mathbf{S} \mathbf{1}$ and $\mathbf{S} 2$ respectively, to reduce computational time. Further the end groups were replaced by a proton as the most neutral substituent.

TD-DFT calculations confirmed that trimer S2-3 had a narrower energy gap (see Table 1) between the calculated HOMO and LUMO (3.54 eV) compared to S1-3 (3.95 eV) Figure 6. Besides, the HOMO levels in both trimers were similar $(-5.17 \mathrm{eV}$ vs. $-5.11 \mathrm{eV})$, the LUMO is more stabilized in the case of $\mathbf{S 2 - 3}$ than in S1-3 (-1.57 eV vs $-1.22 \mathrm{eV})$. To explain this phenomenon and further estimate the effect of either the phenyl or pyridine ring on the respective thiophene unit, the bond length alternation (BLA) for both systems were calculated.

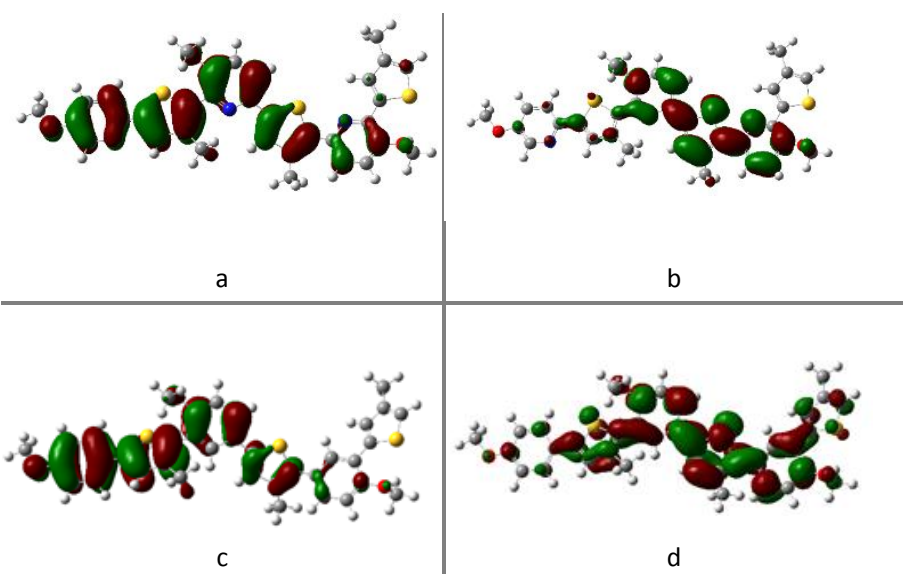

Figure 6. Molecular orbitals (displayed with an isovalue of 0.02). of trimer S1-3: HOMO (a) and LUMO (b) and of trimer S2-3-3: HOMO (c) and LUMO (d).

By comparing the double and single bond lengths in $\pi$ conjugated linear polymers, BLA values can indicate if the ground state is more likely to form a quinoid-like or an aromatic structure. ${ }^{47}$ Since $\mathbf{S 1}$ and $\mathbf{S 2}$ are asymmetric, the BLA calculations were done by only taking the inner thiophene bonds into account. Shorter BLA values of the flanked thiophene in S2-3 (maximum 0.045 $\AA$ ) in comparison to S1-3 (maximum $0.052 \AA$, Table SI-15), and a shorter central carbon bond between the thiophene and phenyl/pyridine of S2-3 (1.467 ̊ vs $1.472 \AA$ ) indicate that the quinoidal structure is more likely formed in $\mathbf{S 2 - 3}$ and explains the stabilization of its LUMO by fortified delocalization of $\pi$-electrons.

\section{Thermal behavior of 01 and 02}

The thermal stability of the polymers was studied by thermogravimetric analysis under $\mathrm{N}_{2}$ at a heating rate of $10 \mathrm{~K} / \mathrm{min}$ in a range from $25-600{ }^{\circ} \mathrm{C}$. 01 lost $59 \%$ of weight at $406{ }^{\circ} \mathrm{C}$ (onset temperature). 02 showed two segments of weight loss: first $4 \%$ weight loss at $221^{\circ} \mathrm{C}$ (onset temperature), probably due to traces of volatiles in the sample; and $50 \%$ weight loss at $405{ }^{\circ} \mathrm{C}$ (onset temperature), directly related to the loss of the alkoxy and alkyl chains.

The DSC thermograms indicated a glass transition temperature of $-7.1{ }^{\circ} \mathrm{C}$ for $\mathbf{O 1}$ and of $25{ }^{\circ} \mathrm{C}$ for $\mathbf{O 2}$.

\section{Electroluminescence experiments}

The oligomers $\mathbf{0 1}$ and $\mathbf{0 2}$ were tested as emissive layer between electrodes in single-layer OLED devices, to prove their electroluminescent properties. The configurations of the devices were ITO/PEDOT:PSS/O1 or 02/LiF/AI. The electroluminescence spectra of both devices (Figure 7) resemble the PL spectra of compounds $\mathbf{0 1}$ and $\mathbf{0 2}$ but they are red shifted (Figure 4 and 7; for 01 shifted from 432 to $533 \mathrm{~nm}$ and for $\mathbf{O 2}$ from 442 to $593 \mathrm{~nm}$ ). These EL spectra are obtained with high applied voltages of $7.7 \mathrm{~V}$ and $10.7 \mathrm{~V}$ (corresponding to $1 \mathrm{~cd} / \mathrm{m}^{2}$ ), respectively. At this voltage, the luminescence of $\mathbf{0 1}$ started to level, indicating an instability of the compound. 02, albeit with a lower luminescence, did not show such a decomposition. Futhermore, a luminance of 2.5 and $0.8 \mathrm{~cd} / \mathrm{m}^{2}$ was achieved at ca. $10 \mathrm{~V}$, respectively and the external quantum yields are quite low presumely due to unbalanced carrier injection and/or transport.

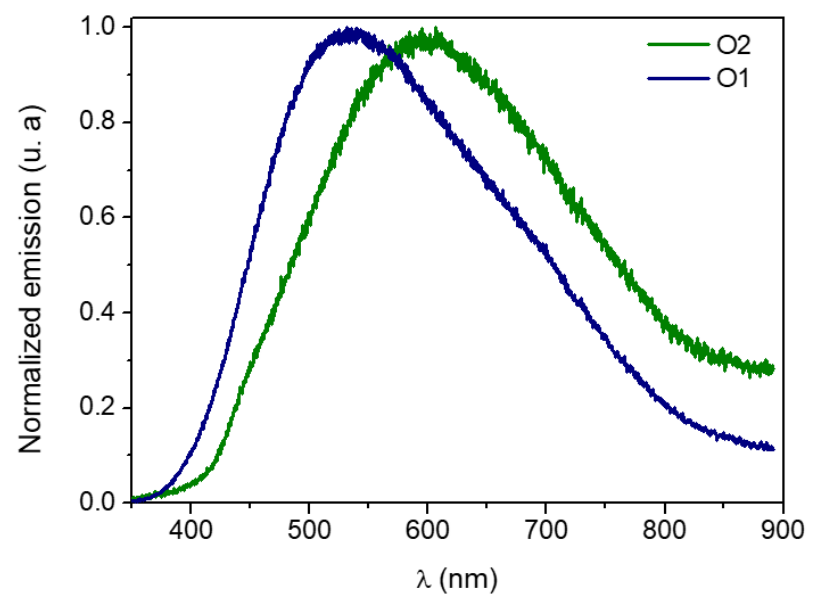

Figure 7. Electroluminescence spectra for the OLED-type devices using $\mathbf{0 1}$ and $\mathbf{0 2}$ as emissive layer.

Effectively, the energy level between the ITO/PEDOT:PSSanode and the oligomers did not match well (with an energy difference of $0.66 \mathrm{eV}$ for $\mathbf{0 2}$ and $0.67 \mathrm{eV}$ for 01, Figure 8). The current densities are high, suggesting that charge carriers move thought the device without many emissive recombination events (see Figure SI- 28 and Table SI- 7). This may be caused by a carrier injection imbalance or a dominant non-radiate recombination in a different layer. Therefore, in order to explore the full potential of oligomers $\mathbf{0 1}$ and $\mathbf{0 2}$, an optimization of the device is required, which is beyond the scope of this study and the object of further investigations. 


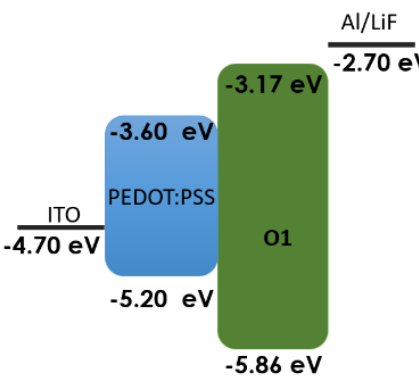

a)

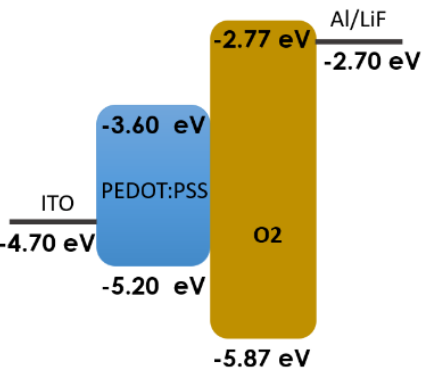

b)
Figure 8. Schematic diagrams of the energy levels of the OLEDs using the oligomers a) $\mathbf{0 1}$ and b) $\mathbf{0 2}$ as emissive layers.

\section{Experimental part}

All the synthesis and characterization of the starting materials and polymers are given in the ESI.

\section{Characterization of the OLED-type devices}

The I-V characterization of the OLED-type devices was performed with a Keithley 2400 Source Measurement Unit, a calibrated photodiode and an Avantes AvaSpec-2048 USB spectrometer.

\section{OLED-type device fabrication.}

ITO coated glass substrates were cleaned in an ultrasonic bath of acetone and isopropanol for $15 \mathrm{~min}$ each. Subsequently, they were dried under a nitrogen stream, heated to $160{ }^{\circ} \mathrm{C}$ for $10 \mathrm{~min}$ and then cleaned with an oxygen plasma with $300 \mathrm{~W}$ for $3 \mathrm{~min}$. $200 \mu \mathrm{L}$ of a PEDOT : PSS solution were spin-coated onto the substrates ( $3500 \mathrm{rpm}$ for $60 \mathrm{~s}$ ). The samples were then transferred into a glovebox and annealed at $150{ }^{\circ} \mathrm{C}$ for $5 \mathrm{~min}$. Afterwards, they were cooled down to $50{ }^{\circ} \mathrm{C}$ over $2 \mathrm{~min}$. A solution of the polymers either in toluene or chloroform was prepared with a concentration of $10 \mathrm{mg} / \mathrm{mL}$. $180 \mu \mathrm{L}$ of the polymer solution were spin coated $(500 \mathrm{rpm}$ for $5 \mathrm{~s}$, and $1000 \mathrm{rpm}$ for $60 \mathrm{~s}$ ) on the PEDOT : PSS layer and the samples were annealed at $70^{\circ} \mathrm{C}$. Finally, a layer of LiF $(1 \mathrm{~nm})$ and $\mathrm{Al}$ $(200 \mathrm{~nm})$ were deposited by thermal evaporation.

\section{Conclusions}

Monomers based on the push pull principle were synthesized using a highly chemo selective Stille reaction between a dinucleophile, containing pyridinyl $\mathbf{5}$, or aryl groups $\mathbf{6}$, and a dielectrophile, which contained a thiophene moiety. Based on those monomers (5 and 6), two oligomers $\mathbf{0 1}$ and $\mathbf{0 2}$ were synthesized using a Suzuki polymerization reaction. Studies analyzing the dependence of molecular weight on conversion showed that the monomers $\mathbf{5}$ and $\mathbf{6}$ may grow in a living fashion, at least until a certain point, $60 \%$ and $40 \%$ respectively, to obtain the oligomers $\mathbf{0 1}$ and $\mathbf{0 2}$. After this point, the catalyst presumably dissociates from the chain. 01 and $\mathbf{0 2}$ showed optical band gaps in solution with values of $3.17 \mathrm{eV}$ and $2.77 \mathrm{eV}$; and quantum yields of $10 \%$ and $28 \%$ respectively. Due to those optoelectronic properties, simple devices to test for electroluminescence with the configuration ITO/PEDOT:PSS/O1 or O2/LiF/Al were fabricated. The devices showed a turn on voltage of 4.3 and $4.6 \mathrm{~V}$ demonstrating the electroluminescent character from the oligomers $\mathbf{0 1}$ and $\mathbf{0 2}$.

\section{Conflicts of interest}

There are no conflicts to declare.

\section{Acknowledgements}

S. U. R. thanks the German Academic Exchange Service (DAAD) and the Colfuturo Fund for a Ph. D. scholarship. Grant number: A/13/72356. M.B. and M.G. acknowledge financial support by the ERC within the project "PhotoSmart" (Starting Grant Agreement 307800).

This research has been supported by the Institutional Strategy of the University of Bremen, funded by the German Excellence Initiative.

\section{Notes and references}

1 K. Müllen and G. Wegner, Electronic Materials: The Oligomer Approach, Wiley-VCH, Weinheim, 1998.

2 T. A. Skotheim and J. Reynolds, Handbook of Conducting Polymers, CRC, Boca-Raton, Fla, 2007.

3 K. Müllen and U. Scherf, Organic Light Emitting Devices: Synthesis, Properties and Applications, Wiley- $\mathrm{VCH}$, Weinheim, 2006.

4 S. Scholz, D. Kondakov, B. Lüssem and K. Leo, Chem. Rev., 2015, 115, 8449-8503.

5 A. C. Grimsdale, K. Leok Chan, R. E. Martin, P. G. Jokisz and A. B. Holmes, Chem. Rev., 2009, 109, 897-1091.

6 M. Grätzel, Inorg. Chem., 2005, 44, 6841-6851.

7 A. Hagfeldt, G. Boschloo, L. Sun, L. Kloo and H. Pettersson, Chem. Rev., 2010, 110, 6595-6663.

8 Y.-J. Cheng, S.-H. Yang and C.-S. Hsu, Chem. Rev., 2009, 109, 5868-5923.

9 H. Sirringhaus, Advanced Materials, 2014, 26, 1319-1335.

10 R. D. McCullough and R. D. Lowe, J. Chem. Soc., Chem. Commun., 1992, DOI: 10.1039/C39920000070, 70-72.

11 M. R. Andersson, O. Thomas, W. Mammo, M. Svensson, M. Theander and O. Inganas, Journal of Materials Chemistry, 1999, 9, 1933-1940.

12 Q. T. Zhang and J. M. Tour, J. Am. Chem. Soc., 1998, 120, 5355-5362.

13 R. D. McCullough, P. C. Ewbank and R. S. Loewe, J. Am. Chem. Soc., 1997, 119, 633-634.

14 B. S. Ong, W. Yiliang and L. Ping, Proceedings of the IEEE, 2005, 93, 1412-1419.

15 I. F. Perepichka, D. F. Perepichka, H. Meng and F. Wudl, Advanced Materials, 2005, 17, 2281-2305.

16 J. Hollinger, A. A. Jahnke, N. Coombs and D. S. Seferos, J. Am. Chem. Soc., 2010, 132, 8546.

17 P. L. Burn, A. B. Holmes, A. Kraft, D. D. C. Bradley, A. R. Brown, R. H. Friend and R. W. Gymer, Nature, 1992, 356, 47.

18 T. Yamamoto, Z.-h. Zhou, T. Kanbara, M. Shimura, K. Kizu, T. Maruyama, Y. Nakamura, T. Fukuda, B.-L. Lee, N. Ooba, S. Tomaru, T. Kurihara, T. Kaino, K. Kubota and S. Sasaki, J. Am. Chem. Soc., 1996, 118, 10389-10399. 
19 E. E. Sheina, J. S. Liu, M. C. lovu, D. W. Laird and R. D. McCullough, Macromolecules, 2004, 37, 3526-3528.

20 A. Yokoyama, R. Miyakoshi and T. Yokozawa, Macromolecules, 2004, 37, 1169-1171.

21 I. Osaka and R. D. McCullough, Acc. Chem. Res., 2008, 41, 1202-1214

22 22. T. Yokozawa, Y. Nanashima, H. Kohno, R. Suzuki, M. Nojima and Y. Ohta, Pure Appl. Chem, 2013, 85, 573-587.

23 23. S. Govaerts, P. Verstappen, H. Penxten, M. Defour, B. Van Mele, L. Lutsen, D. Vanderzande and W. Maes, Macromolecules, 2016, 49, 6411-6419.

24 M. Se'vignon, J. Papillon, E. Schulz and M. Lemaire, Tetrahedron Lett., 1999, 40, 5873-5876.

25 Q. Wang, R. Takita, Y. Kikuzaki and F. Ozawa, J. Am. Chem. Soc., 2010, 132, 11420-11421.

26 K. Okamoto, J. Zhang, J. B. Housekeeper, S. R. Marder and C. K. Luscombe, Macromolecules, 2013, 46, 8059-8078.

27 M. Lafrance and K. Fagnou, J. Am. Chem. Soc., 2006, 128, 16496-16497.

28 S. Tamba, S. Mitsuda, F. Tanaka, A. Sugie and A. Mori, Organometallics, 2012, 31, 2263-2267.

29 R. Matsidik, J. Martin, S. Schmidt, J. Obermayer, F. Lombeck, F. Nübling, H. Komber, D. Fazzi and M. Sommer, J. Org. Chem., 2015, 80, 980-987.

30 Y. Tokita, M. Katoh, Y. Ohta and T. Yokozawa, Chem. Eur. J., 2016, 22, 17436-17444.

31 A. C. J. Heinrich, B. Thiedemann, P. J. Gates and A. Staubitz, Org. Lett., 2013, 15, 4666-4669.

32 H.-H. Zhang, Y.-X. Zhu, W. Wang, J. Zhu, P. V. Bonnesen and K. Hong, Polymer Chemistry, 2018, 9, 3342-3346.

33 R. S. Loewe and R. D. McCullough, Chemistry of Materials, 2000, 12, 3214-3221.

34 R. S. Loewe, P. C. Ewbank, J. S. Liu, L. Zhai and R. D. McCullough, Macromolecules, 2001, 34, 4324-4333.

35 A. Kiriy, V. Senkovskyy and M. Sommer, Macromolecular Rapid Communications, 2011, 32, 1503-1517.

36 A. A. El-Shehawy, N. I. Abdo, A. A. El-Barbary and J.-S. Lee, Tetrahedron Lett., 2010, 51, 4526-4529.

37 T. Ross Kelly, Q. Li and V. Bhushan, Tetrahedron Lett., 1990 31, 161-164.

38 J. Y. Hwang, L. A. Arnold, F. Zhu, A. Kosinski, T. J. Mangano, V. Setola, B. L. Roth and R. K. Guy, Journal of Medicinal Chemistry, 2009, 52, 3892-3901.

39 M. S. Yusubov, E. N. Tveryakova, E. A. Krasnokutskaya, I. A Perederyna and V. V. Zhdankin, Synthetic Communications, 2007, 37, 1259-1265.

40 A. K. Parhi, A. Xiang, J. D. Bauman, D. Patel, R. S. Vijayan, K. Das, E. Arnold and E. J. Lavoie, Bioorg Med Chem, 2013, 21 6435-6446.

41 J. Linshoeft, A. C. J. Heinrich, S. A. W. Segler, P. J. Gates and A. Staubitz, Org. Lett., 2012, 14, 5644-5647.

$42 \mathrm{H}$. Noguchi, K. Hojo and M. Suginome, J. Am. Chem. Soc., 2007, 129, 758-759.

43 A similar deviation from linearity has been observed for high monomer to catalyst loadings in ref. 19. Other researchers also report a high dependence on the catalyst whether and how much linearity is observed in this type of plot: M.-P. Van Den Eede, J. De Winter, P. Gerbaux and G. Koeckelberghs, Macromolecules, 2018, 51, 9043-9051.

44 S. Gondo, Y. Goto and M. Era, Molecular Crystals and Liquid Crystals, 2007, 470, 353-358.

45 D. Khlaifia, C. P. Ewels, F. Massuyeau, M. Chemek, E. Faulques, J.-L. Duvail and K. Alimi, RSC Advances, 2016, 6 56174-56182.

46 C. M. Cardona, W. Li, A. E. Kaifer, D. Stockdale and G. C. Bazan, Advanced Materials, 2011, 23, 2367-2371.

47 J. L. Brédas, The Journal of Chemical Physics, 1985, 82, 38083811. 